\title{
Persistence and Remission of Musculoskeletal Pain in Community-Dwelling Older Adults: Results from the Cardiovascular Health Study
}

\author{
Stephen M. Thielke, MD, MSPH, ${ }^{a, b}$ Heather Whitson, MD, MHS, ${ }^{c, d}$ Paula Diehr, PhD, ,f Ann \\ O'Hare, MD, MA, ${ }^{, h}$ Patricia M. Kearney, PhD, ${ }^{i}$ Sarwat I. Chaudhry, MD, ${ }^{j}$ Neil A. Zakai, MD, \\ MSc, ${ }^{k, l}$ Dae Kim, MD, MPH, ${ }^{m}$ Nishant Sekaran, MD, ${ }^{n}$ Joanna E. M. Sale, PhD, ${ }^{o}$ Alice M. Arnold, \\ PhD, ${ }^{e}$ Paulo Chaves, MD, PhD, ${ }^{p}$ and Anne Newman, MD, $\mathrm{MPH}^{q}$
}

OBJECTIVES: To characterize longitudinal patterns of musculoskeletal pain in a community sample of older adults over a 6-year period and to identify factors associated with persistence of pain.

DESIGN: Secondary analysis of the Cardiovascular Health Study.

SETTING: Community-based cohort drawn from four U.S. counties.

PARTICIPANTS: Five thousand ninety-three men and women aged 65 and older.

MEASUREMENTS: Over a 6-year period, pain was assessed each year using a single question about the

From the ${ }^{a}$ Departments of Psychiatry and Behavioral Sciences, University

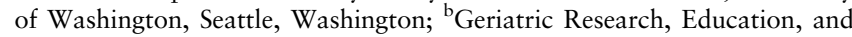
Clinical Center, Puget Sound Veterans Affairs Medical Center, Seattle,

Washington; ${ }^{\mathrm{c}}$ Department of Medicine (Geriatrics) and the Aging Center, Duke University Medical Center, Durham, North Carolina; ${ }^{\mathrm{d}}$ Geriatric

Research, Education, and Clinical Center, Durham VA Medical Center,

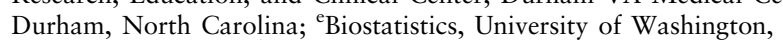

Seattle, Washington; fHealth Services, University of Washington, Seattle, Washington; ${ }^{\mathrm{g} D i v i s i o n}$ of Nephrology, University of Washington, Seattle, Washington; hepartment of Hospital and Speciality Medicine, Veterans Affairs Puget Sound Health Care System and Group Health Research Institute, Seattle, Washington; ${ }^{\mathrm{i}}$ Department of Epidemiology and Public Health, University College Cork, Cork, Ireland; ${ }^{j}$ Department of Internal Medicine, Yale University, New Haven, Connecticut; ${ }^{k}$ Departments of Medicine, College of Medicine, University of Vermont, Burlington, Vermont; 'Pathology, College of Medicine, University of Vermont, Burlington, Vermont; ${ }^{\mathrm{m}}$ Division of Gerontology, Beth Israel Deaconess Medical Center, Harvard Medical School, Boston, Massachusetts;

${ }^{\mathrm{n}}$ Division of General Internal Medicine, University of Michigan, Ann Arbor, Michigan; ${ }^{\circ}$ Mobility Program Clinical Research Unit, Li KaShing Knowledge Institute, St. Michael's Hospital, Toronto, Canada; ${ }^{\mathrm{P} B e n j a m i n}$ Leon Jr. Family Center for Geriatric Research and Education, Herbert Wertheim College of Medicine, Florida International University, Miami, Florida; and ${ }^{9}$ Department of Epidemiology, University of Pittsburgh, Pittsburgh, Pennsylvania.

Address correspondence to Stephen Thielke, Psychiatry and Behavioral Sciences, University of Washington, Seattle, WA 98195.

E-mail sthielke@u.washington.edu

DOI: 10.1111/j.1532-5415.2012.04082.x presence of pain in any bones or joints during the last year. If affirmative, participants were queried about pain in seven locations (hands, shoulders, neck, back, hips, knees, feet). Participants were categorized according to the percentage of time that pain was present and according to the intermittent or chronic pattern of pain. Factors associated with persistent pain during five remaining years of the study were identified.

RESULTS: Over 6 years, $32 \%$ of participants reported pain for three or more consecutive years, and $32 \%$ reported pain intermittently. Of those who reported pain the first year, $54 \%$ were pain free at least once during the follow-up period. Most of the pain at specific body locations was intermittent. Factors associated with remission of pain over 5 years included older age, male sex, better self-rated health, not being obese, taking fewer medications, and having fewer depressive symptoms. Approximately half of those with pain reported fewer pain locations the following year.

CONCLUSION: Musculoskeletal pain in older adults, despite high prevalence, is often intermittent. The findings refute the notion that pain is an inevitable, unremitting, or progressive consequence of aging. J Am Geriatr Soc 60:1393-1400, 2012.

Key words: pain; musculoskeletal; longitudinal analysis; remission; persistence; symptoms

$T$ he high prevalence of bone and joint pain in older adults $^{1,2}$ has contributed to the assumption that it may be an unfortunate dividend of growing older. ${ }^{3}$ Many older adults identify joint pain as a normal part of life, ${ }^{4}$ with such statements as, "That's how you know you're alive... you ache." ${ }^{5}$ Providers may be complicit, suggesting that people get used to joint pain because "it's only going 
to get worse." 6 The expectation that aging adults accumulate "wear and tear" mechanical injury, with no potential for effective remedy except joint replacement, reinforces the expectation that, as people age, they will experience pain.

In a recent study of 502 British adults aged 50 and older with musculoskeletal pain, $82 \%$ believed that receiving information about the prognosis of their pain was important, but only $33 \%$ reported discussing prognosis with their general practitioner. ${ }^{7}$ These individuals reported that a prognosis could help them to plan for future activity and to know for the sake of knowing. They felt discouraged from seeking prognostic information because they believed that progression of pain was inevitable, that pain could not be accurately predicted, and that nothing could be done to help them.

Previous research has not characterized the longitudinal course or predictors of persistent musculoskeletal pain in older adults well. Early studies focused more on radiographic findings than pain. ${ }^{8}$ Community-based studies have mainly measured the prevalence of musculoskeletal pain at a single time point or using a single follow-up, rather than its longitudinal course. ${ }^{9-13}$ Studies that monitor outcomes over time have generally recruited participants from clinical rather than community settings, generating conflicting results about the effects of age and other factors on prognosis. ${ }^{14,15}$ The current study was designed to characterize the frequency, longitudinal course, and predictors of persistence of musculoskeletal pain in a community cohort of older adults.

\section{METHODS}

\section{Participants}

The Cardiovascular Health Study (CHS) is an ongoing observational study of ambulatory, community-dwelling older adults. Participants were recruited from Medicare enrollment lists in four U.S. communities. Potential participants were excluded if they resided in an institution, were not ambulatory, could not be interviewed, were receiving hospice care or radiation or chemotherapy for cancer, or were not expected to live in the area for 3 years. Further details of the design and sampling methods have been published previously. ${ }^{16}$ Between 1989 and 1990, 5,201 participants were enrolled. In 1992 and 1993, in an effort to increase representation of ethnic minorities, an additional 687 African-American participants were recruited.

Each year until 1999/2000, participants received inperson annual examinations and were administered measures of health, physical and mental health symptoms, diagnoses, physiological parameters, functioning, and social support. Questions on bone and joint pain were completed in the baseline, third, and fifth through tenth years of the study for all participants, with the AfricanAmerican cohort entering in the fifth year. To include all of the participants and to analyze sequential measurements of pain, 1994/95 was considered as the index or baseline year, and the yearly measurements from the next 5 years were analyzed. The numerical label for each year thus represents the number of years from the index year (e.g., $1997 / 98$ is year 4).
The institutional review board (IRB) at each site approved the original study. The IRB at the University of Washington approved secondary data analyses.

\section{Measurements}

\section{Pain}

Musculoskeletal pain was assessed using a single yes/no question: "Have you had pain in your bones or joints in the last year?" If participants answered yes, then interviewers asked whether they had had pain in seven different body locations: hands, shoulders, neck, back, hips, knees, and feet.

\section{Sociodemographic Covariates}

Data about age, sex, race (dichotomized as white vs nonwhite), marital status (dichotomized as married or partnered vs single), and education (categorized as high school or less, high school graduate, some college, and college graduate) were collected.

\section{Other Covariates}

Based on previously demonstrated associations with health status, functioning, and pain, ${ }^{17-19}$ and preliminary analyses of covariates, four covariates were selected. Self-rated health was assessed by asking participants, "Would you consider your health in general to be excellent, very good, good, fair, or poor?" For categorical analyses, these were dichotomized as excellent, very good, or good vs fair or poor. $^{20}$ Body mass index (BMI) was computed using measured height and weight and categorized as underweight $\left(<18.5 \mathrm{~kg} / \mathrm{m}^{2}\right)$, normal weight $\left(18.5-24.9 \mathrm{~kg} / \mathrm{m}^{2}\right)$, overweight $\left(25.0-29.9 \mathrm{~kg} / \mathrm{m}^{2}\right)$, and obese $\left(\geq 30.0 \mathrm{~kg} / \mathrm{m}^{2}\right)$. Depression was measured using the 10-item Center for Epidemiological Studies Depression Scale (CES-D). ${ }^{21}$ Each item was rated between 0 (none of the time or rarely) and 3 (most of the time), and they were summed, yielding a maximum score of 30 . Participants were categorized as having no or few depressive symptoms (score $<5$ ), some depressive symptoms (score 5-10), and significant depressive symptoms (score $>10$ ). Number of prescribed medications was determined by asking participants to bring all of their medications to the study appointment and cataloguing them. These were categorized as none, one or two, three to five, and six or more medications, as in other CHS studies. ${ }^{22}$ Analgesic medications were not categorized separately. To characterize the sample, participants with and without pain we compared using different categories of cognitive status (according to Mini-Mental State Examination score) and self-report of medication to treat arthritis (from the question, "Do you have arthritis treated with medication?").

\section{Analysis}

The goals of this analysis were to characterize how often pain occurred in CHS participants and the factors it was associated with at baseline; to categorize participants according to the amount of time they reported pain and whether the pain was chronic or intermittent; to identify 
factors associated with persistent report of pain over 5 years of follow-up; to examine how often participants reported more, the same number, or fewer locations of pain during 1-year intervals; and to estimate the association of number of pain locations with persistent report of any pain.

\section{Descriptive Statistics}

The percentages of participants who did and did not report pain in the index year were compared, grouped according to the covariates, using a $t$-test or chi square test, and the percentage of participants who reported pain at each of the seven body locations was computed.

\section{Categories of Pain Persistence}

For any pain and the seven body locations, participants were categorized according to the number of observations in which they reported pain, between none of the time and all the time. Years with missing pain scores were not included in the denominator, and the results represent the percentage of all the observations during which pain was reported. Variables were created to identify participants with chronic and intermittent pain. Chronic pain was defined as report of pain during three or more observations in a row; missing years were not counted, so the observations of pain could be 2 or more years apart with missing values in between. Intermittent pain was defined as 2 or more total years in which pain was reported, with at least 1 year in which pain was not reported, and not for 3 years in a row. Participants with fewer than three observations were not counted for estimating the percentages.

\section{Factors Associated with Persistent Report of Pain}

Discrete time Cox proportional hazards models estimated the probability of participants continuing to report any pain over the 6 years of observation. For those with pain in the index year, time to remission was calculated as the first observation at which the participant denied having any pain, regardless of specific locations. Censoring occurred at the time of the last visit or death. Three separate Cox proportional hazards models were constructed. The first used only the sociodemographic variables, the second used these variables plus each of the other health factors entered individually, and the third used all the variables combined. Time-varying covariates were used for self-rated health, depression score, and number of medications. $^{23}$ For any significant predictors, the proportional hazards assumption was tested by visual inspection of stratified survival curves.

\section{Effect of Number of Pain Locations}

The primary outcome was persistence or remission of pain, which does not account for the number of pain locations. In other research, number of pain sites has been strongly associated with pain interference and sequelae. ${ }^{24,25}$ Number of pain sites was thus examined separately. The probability of complete remission of all pain at 1 year and the likelihood of persistent pain during the follow-up period were estimated for each different number of bodily pain locations (between 1 and 7 ). The probability of a reduction in number of pain sites at 1 year was also computed. A logistic generalized estimating equation model, controlling for sociodemographic factors, estimated the association between number of pain sites and likelihood of reporting no years without pain.

Analyses were conducted using PASW Statistics version 18.0 (IBM Software, New York, NY) for the descriptive and survival analyses and Stata version 11.0 (Statacorp, College Station, TX) for analyses of pain sites.

\section{RESULTS}

Of the 5,093 participants alive in the index year, 4,974 had a pain score recorded that year. In the index year, $11 \%$ of the participants were aged $70-74,46 \%$ were $75-79,26 \%$ were $80-84,13 \%$ were $85-89$, and $4 \%$ were 90 and older. During the 5 years of follow-up, 978 participants died. Approximately $3 \%$ of the participants did not have a pain measure recorded at each year; $1.4 \%$ of participants who had a pain measure recorded in the index year and remained alive had no additional pain measures, and $4.1 \%$ had no follow-up because they had died. There was no difference in missingness based on initial pain status. The annual probability of death, grouped according to any pain or specific pain location, was between $4 \%$ and $5 \%$; using the chi-square test, there was no statistically significant difference in the annual probability of death depending on the presence or absence of pain.

\section{Prevalence of Pain}

In the index year, $42 \%$ of participants reported musculoskeletal pain. Table 1 compares groups with and without pain. There was no difference in the mean age of those with and without pain. Participants who reported pain were more likely to have less than a college education, to take three or more medications, to be obese, to report fair or poor self-rated health, and to have some or significant depressive symptoms than those without pain.

\section{Longitudinal Patterns of Pain}

Table 2 shows the prevalence of pain in the index year and the percentage of time in which participants reported pain during 6 years of follow-up. Twenty one percent of participants never reported any pain, $17 \%$ reported pain at all observations, $32 \%$ reported pain chronically (during $\geq 3$ sequential years), and $32 \%$ reported pain intermittently (more than once but not 3 years in a row). There was little difference between the different pain locations, except that pain in the neck and feet were less common than the others. Chronic pain at the individual locations was less common than chronic pain involving any site, with no more than $10 \%$ of participants describing chronic pain in any particular location. The majority of pain at specific body locations was intermittent.

\section{Factors Associated with Time to First Remission}

During the 5 -year follow-up period, $54 \%$ of those who had pain in the index year were observed to have at least 1 year without pain. Using a survival model with redistri- 
Table 1. Prevalence of Musculoskeletal Pain in Participants in Index Year, Categorized According to Sociodemographic and Health-Related Factors

\begin{tabular}{|c|c|c|c|}
\hline Characteristic & With Pain & Without Pain & $P$-Value \\
\hline Age, mean \pm standard deviation & $77.4 \pm 5.3$ & $77.6 \pm 5.5$ & .10 \\
\hline Female, n (\%) & $1,349(66)$ & $1,640(54)$ & $<.001$ \\
\hline White, $\mathrm{n}(\%)$ & $1,715(84)$ & $2,477(81)$ & .06 \\
\hline Married or partnered, N (\%) & $1,262(62)$ & $1,817(60)$ & .18 \\
\hline \multicolumn{4}{|l|}{ Education, $\mathrm{n}(\%)(\mathrm{N}=5,079)$} \\
\hline$<$ High school & $597(29)$ & $833(27)$ & 16 \\
\hline High school & $557(27)$ & $815(27)$ & .38 \\
\hline Some college & $506(25)$ & $692(23)$ & .11 \\
\hline College graduate & $385(19)$ & $694(23)$ & .001 \\
\hline \multicolumn{4}{|l|}{ Self-rated health, $n(\%)(N=5,088)$} \\
\hline Excellent to very good & $569(28)$ & $1,393(46)$ & $<.001$ \\
\hline Good & $882(43)$ & $1,213(40)$ & .03 \\
\hline Fair to poor & $598(29)$ & $533(18)$ & $<.001$ \\
\hline \multicolumn{4}{|c|}{ Number of medications, $n(\%)(N=5,055)$} \\
\hline 0 & $281(14)$ & $729(24)$ & $<.001$ \\
\hline $1-2$ & $699(34)$ & $1,144(38)$ & .02 \\
\hline $3-5$ & $763(38)$ & $891(29)$ & $<.001$ \\
\hline$\geq 6$ & $290(14)$ & $258(9)$ & $<.001$ \\
\hline \multicolumn{4}{|c|}{ Body mass index, $\mathrm{kg} / \mathrm{m}^{2}, \mathrm{n}(\%)(\mathrm{N}=5,089)$} \\
\hline$<18.5$ (underweight) & $26(1)$ & $47(2)$ & .28 \\
\hline 18.5-24.9 (normal weight) & $637(31)$ & $1,207(40)$ & $<.001$ \\
\hline $25.0-29.9$ (overweight) & $851(41)$ & $1,273(42)$ & .38 \\
\hline$\geq 30.0$ (obese) & $537(26)$ & $511(17)$ & $<.001$ \\
\hline \multicolumn{4}{|c|}{ Depressive symptoms (Center for Epidemiologic Studies Depression Scale score), $\mathrm{n}(\%)(\mathrm{N}=4,965)$} \\
\hline None or few $(\leq 4)$ & $872(43)$ & $1,738(59)$ & $<.001$ \\
\hline Some $(5-10)$ & $715(35)$ & $925(31)$ & .006 \\
\hline Significant $(>10)$ & $416(20)$ & $299(10)$ & $<.001$ \\
\hline \multicolumn{4}{|c|}{ Cognitive impairment (Mini-Mental State Examination Score), n (\%) $(N=4,249)$} \\
\hline Unlikely (> 23) & $1,591(94)$ & $2,332(92)$ & .02 \\
\hline Likely (15-23) & $92(5.4)$ & $183(7.2)$ & .34 \\
\hline Significant $(<15)$ & $17(1.0)$ & $34(1.3)$ & .40 \\
\hline \multicolumn{4}{|c|}{ Medication to treat arthritis, $\mathrm{n}(\%)(\mathrm{N}=4,517)$} \\
\hline No & $981(54)$ & $2,283(84)$ & $<.001$ \\
\hline Yes & $829(46)$ & $424(16)$ & $<.001$ \\
\hline
\end{tabular}

Table 2. Pain Prevalence in the Index Year and Categories of Pain Persistence During 6 Years of Follow-Up

$\%$

\begin{tabular}{lccccccrr}
\multicolumn{1}{c}{ Category } & Any Site & Hands & Shoulders & Neck & Back & Hips & Knees & Feet \\
\hline Index year & 42 & 18 & 16 & 12 & 19 & 16 & 20 & 11 \\
Observations with pain, \% (over 6 years) & & & & & & & & \\
0 & 21 & 54 & 54 & 65 & 51 & 56 & 49 & 65 \\
$17-25$ & 16 & 15 & 17 & 14 & 16 & 16 & 16 & 15 \\
$33-50$ & 22 & 15 & 16 & 11 & 16 & 14 & 15 & 11 \\
$60-83$ & 24 & 11 & 10 & 7 & 11 & 10 & 12 & 7 \\
100 & 17 & 6 & 4 & 3 & 6 & 5 & 8 & 3 \\
Intermittent pain $^{\text {a }}$ & 32 & 23 & 23 & 16 & 25 & 23 & 27 & 18 \\
Chronic pain $^{b}$ & 32 & 9 & 7 & 5 & 8 & 7 & 10 & 4 \\
\hline
\end{tabular}

${ }^{a}$ Pain reported two or more times, but not 3 years in a row, as a percentage of participants with three or more observations.

${ }^{b}$ Pain reported at three or more observations in a row as a percentage of participants with three or more observations.

bution from censoring, $48 \%$ of those with pain in the index year were estimated to report no pain at least once during the 5 years of follow-up. Table 3 shows the results of a Cox proportional hazards models adjusted and unadjusted. Older age and male sex were associated with statistically significantly greater likelihood of pain resolving at any subsequent year. Worse self-rated health and obesity (but not overweight) were strongly associated with longer time to remission. Significant depressive symptoms and more medications were also associated with less likelihood of pain resolving. Stratified survival plots for these factors indicated that the hazards remained similar throughout follow-up and that the proportional hazards assumption was not violated. 


\section{Pain Sites}

The prevalence of pain according to site in the index year is reported in Table 2. The median number of pain sites per participant in the index year was 3 . Women reported significantly more pain sites than men (mean 3.2 vs 2.6 , $P<.001$ ). Table 4 shows the prevalence of the different numbers of pain sites, the likelihood of remission of pain over 1-year intervals, the likelihood of a reduction in the number of pain sites over 1-year intervals, and the likelihood of any additional year without any pain. Those with pain at more locations were less likely to report no pain in the following year and less likely to have at least 1 year without pain, but they were equally likely to have a reduction in the number of pain locations.

Roughly half of participants in all groups based on number of pain sites reported fewer pain sites the following year, including those who reported pain at all seven sites. Women were significantly less likely than men to show a reduction in pain sites at the following year (odds ratio $=0.86,95 \%$ confidence interval $(\mathrm{CI})=0.78$ $0.96, P=.005)$. A generalized estimating equation model controlling for age, sex, race, and marital status showed that each additional pain site in the index year was associated with an OR of $1.39(95 \%$ CI $=1.32-1.46)$ for a persistent report of pain throughout the follow-up period.

\section{DISCUSSION}

In this large community sample of older adults tracked for 6 years, approximately one in five participants never reported musculoskeletal pain, approximately one in six reported pain every year, approximately one-third had chronic pain, and approximately one-third had intermittent pain. Approximately half of those who initially reported pain reported not having pain at least once during the five subsequent observations. The majority of pain at specific body locations was intermittent, and little of it was chronic. No particular location of pain was highly prevalent or highly likely to persist. These findings suggest that pain is a more-dynamic symptom in communitydwelling older adults than may be commonly thought. They challenge the conception of musculoskeletal pain as a fixed, chronic symptom during aging and the assumption that, once present, pain remains stable or worsens.

These results may have several clinical implications. First, prognosis is important for patients, ${ }^{7}$ and instead of promoting the idea that they should "get used to it because it's just going to get worse," as one woman described her doctor's advice, ${ }^{6}$ clinicians might offer a more evidence-based perspective on the future course of pain and emphasize its dynamic nature. Second, identifying and addressing modifiable risk factors might increase the likelihood of remission. Treating depression may improve pain symptoms. ${ }^{26,27}$ Obesity can be addressed and may have a direct mechanical relationship with pain. Self-rated health may be difficult to influence, but its association with pain suggests the broad potential benefits of health promotion. Third, clinicians might collaborate with patients to project the anticipated duration of analgesic therapy and to agree on how to evaluate response. Especially given the risks associated with chronic opioid therapy ${ }^{28}$ it seems important for clinicians not to assume that

\section{Table 3. Cox Proportional Hazards Model of Factors Associated with Time to Remission of Musculoskeletal Pain During 5-Year Follow-Up Period, Using Time-Varying Covariates for Self-Rated Health, Depression Score, and Number of Medications, for Participants Who Reported Pain in the Index Year}

Hazard Ratio of Pain Resolving (95\% Confidence Interval) $P$-value

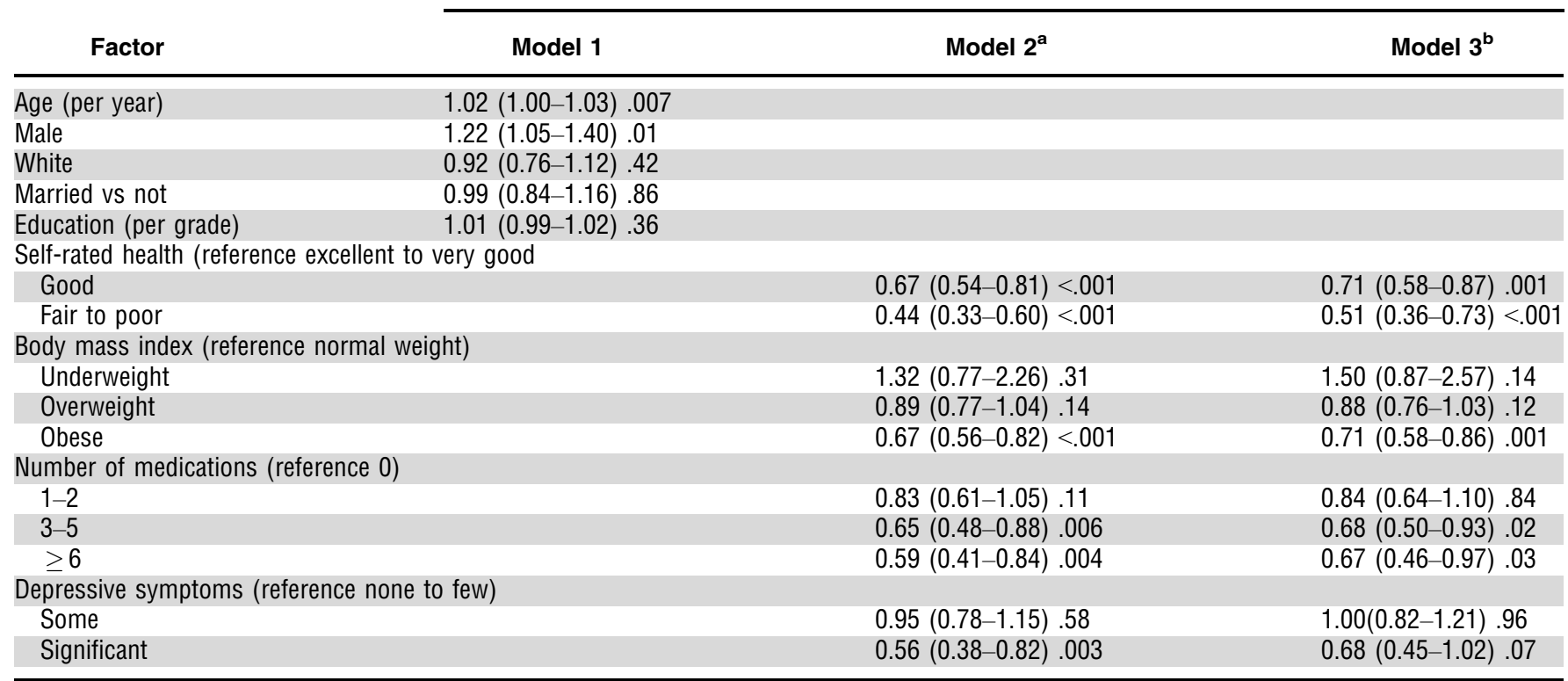

\footnotetext{
${ }^{\text {a }}$ Controlled for sociodemographic factors.

${ }^{\mathrm{b}}$ Controlled for sociodemographic factors and other variables.
} 
Table 4. Remission of Musculoskeletal Pain According to Number of Pain Sites

$\%$

\begin{tabular}{|c|c|c|c|c|}
\hline $\begin{array}{c}\text { Number } \\
\text { of Pain } \\
\text { Sites }\end{array}$ & $\begin{array}{c}\text { Any Pain, } \mathbf{n} \\
\text { (\%) }\end{array}$ & $\begin{array}{c}\text { Complete } \\
\text { Resolution } \\
\text { of Pain at } \\
1 \text { Year }\end{array}$ & $\begin{array}{c}\text { Fewer Pain } \\
\text { Sites } 1 \text { Year } \\
\text { Later } \\
\text { (Including } \\
\text { Complete } \\
\text { Resolution) }\end{array}$ & $\begin{array}{c}\geq 1 \text { Years } \\
\text { without } \\
\text { Pain } \\
\text { During } \\
5-\text { Year } \\
\text { Follow-Up } \\
\text { Period }\end{array}$ \\
\hline 1 & $6,272(30)$ & 43 & 43 & 62 \\
\hline 2 & $4,287(21)$ & 29 & 50 & 51 \\
\hline 3 & $3,172(15)$ & 21 & 52 & 44 \\
\hline 4 & 2,576 (12) & 18 & 56 & 38 \\
\hline 5 & $1,713(8)$ & 14 & 57 & 31 \\
\hline 6 & 1,337 (6) & 10 & 61 & 24 \\
\hline 7 & $1,880(9)$ & 8 & 49 & 18 \\
\hline Any & $21,118(100)$ & 25 & 49 & 46 \\
\hline
\end{tabular}

$\mathrm{n}=$ number of total participant observations over 6 years, with participants counted multiple times.

musculoskeletal pain in older adults, being the result of progressive wear and tear, is intractable and demands perpetual treatment.

This research offers additional perspective on the association between pain and aging. The finding of a small, positive association between older age and likelihood of remission (Tables 1 and 3 ) argues that pain is not a normal part of the aging process. This association persisted after controlling for other sociodemographic and healthrelated factors, suggesting that it is not a result of health status or other covariates. Although these results contradict some assumptions about pain in aging, they are overall consistent with previous studies, which show no increase in reports of pain with age. ${ }^{13,29-31}$ A meta-analysis of differences in pain perception with advancing age found that the highest prevalence of chronic pain occurred at approximately age 65 , after which there was a slight decline with advancing age, even past age $85 .{ }^{29}$ In a British cohort, individuals who were retired were less likely to develop chronic pain. ${ }^{13}$ Other research regarding pain during the last 2 years of life found that, although arthritis pain was common, the prevalence of pain was inversely correlated with advancing age. ${ }^{32,33}$

Some longitudinal studies have reported a slow and steady progression of musculoskeletal pain with age. ${ }^{34,35}$ Several factors probably influenced the current study's contrasting results. First, the CHS sample consisted of community-dwelling older adults and not people who presented to specialty clinics with symptoms, who may have more-severe pain or pathology. ${ }^{36}$ Second, this research concentrated on self-report of pain rather than diagnosis of osteoarthritis or other underlying pathology. There is a variable association between bone and joint pain and radiographic evidence or clinician diagnosis, ${ }^{37,38}$ and prior studies have mainly used radiographic measures to evaluate longitudinal course. ${ }^{39}$ Third, the repeat measures on the same individuals in this study identified dynamic changes over time rather than population-level effects.
The definition of pain used in these analyses, based on a question about any pain in the bones and joints, followed by questions about seven specific body locations, is important in interpreting the results. It may mask differences in the intensity, cause, or consequences of pain. Other research has defined pain based on number of pain locations, analyzed as a count ${ }^{12}$ or categorized as no pain, a single site, or widespread pain. ${ }^{40}$ The current analysis indicates, like these other studies, that single-location pain may be different from pain at multiple sites; at the same time, it showed a high likelihood of remission even in participants with pain at many sites (Table 4). It is also important to differentiate report of any pain from the interference that pain causes, and there is evidence from large community samples that pain interference may increase consistently with age even as incidence of pain does not change. ${ }^{41}$ That work was not longitudinal and may not have captured dynamic changes in pain interference. Different measures of pain have different meanings and relevance, and additional research can help ascertain how pain, pain interference, and the reporting of pain change over time.

This analysis was not able to ascertain whether participants' pain remitted spontaneously; they may have had medical, surgical, or behavioral interventions between measurements. Many treatment modalities, including nonpharmacological approaches such as exercise, have evidence-based benefits for bone and joint pain. ${ }^{42-44}$ Analgesic medications were not included in the models because this analysis focused on course over time rather than treatment response. Adequately accounting for medications requires detailed separate analyses (e.g., accounting for pain and medication across two time points creates four categories instead of two), and many analgesic medications, especially opiates, are taken for short periods of time $^{45}$ and are difficult to map into pain measures. Future research is warranted to clarify what factors are associated with more and less remission and how various interventions, in particular analgesics, influence persistence of musculoskeletal pain.

The higher prevalence of musculoskeletal pain and the lower likelihood of pain resolution in women than men in this sample mirrors similar results of other studies. ${ }^{46,47}$ Despite statistically significant results, the absolute differences between women and men were not dramatic and were less than the differences in the other variables such as depression, obesity, medications, and self-rated health. There may be sex-mediated social or psychological factors related to the experience and report of pain that were not measured in the present study, and additional research is warranted to understand how women and men show different patterns of pain across time and how they respond to treatments.

\section{Limitations}

This study has several limitations. First, the CHS questions about pain in any bone or joint asked for a yes/no response and did not assess degree of or the interference caused by pain, as measured in instruments such as the Medical Outcomes Study 36-item Short-Form Survey. ${ }^{48}$ Psychometric analyses have not characterized this single 
question well. An affirmative answer was assumed to be a marker for a clinically significant symptom, and a negative answer was taken as evidence that the participant was not experiencing distress from pain. The analyses examining number of pain locations offered an indirect proxy for severity, based on previous research about pain locations. ${ }^{12}$ Some important types of pain may have been omitted, especially headache, which was not measured in the CHS cohort. Second, pain was assessed every year, and pain status may have fluctuated more frequently. Pain may be even more dynamic than this analysis found. Third, there were no objective measures of joint pathology to compare with reports of pain. Fourth, treatments for pain were not included, for instance, if participants with hip or knee pain had undergone joint replacement between study years or if they were taking analgesic medications. Although this may have happened in some cases, the facts that all the body locations were similar, whether or not surgical treatments exist for them, that those who took medications were more like to report pain (Table 1), and that greater medication use was associated with less likelihood of remission of pain, indicate that treatments did not primarily or uniformly determine the changes in pain status. Fifth, there were some missing pain data; $3 \%$ of pain measures were missing in the index year, and during the remaining years, $2.9 \%$ of those who did not report pain and $3.1 \%$ of those who reported pain had missing pain data at the following year. There was no clear difference in missingness or death based on pain status. Sixth, the adjusted models deliberately did not include comorbidities, which may have led to confounding due to health status. Comorbidities were not included for several reasons. Pathophysiological correlations between bone and joint pain and other chronic medical conditions seemed unlikely. Preliminary analyses confirmed a lack of association; a model that included nine specific comorbidities found that none of these variables, nor an aggregate score from them, was significantly associated with persistent report of pain. Seventh, number of medications and self-rated health are strongly collinear with comorbidities, and these probably adequately adjusted for health status. ${ }^{49}$ Finally, individuals with cognitive impairments may not be able to report historical pain reliably. This was unlikely to influence the main findings, because the rate of cognitive impairment was low in this sample, self-report characterizes current pain even in the setting of cognitive impairment, and the differences between rates of self-reported and observed pain are generally not large even in individuals with dementia. ${ }^{50}$

\section{CONCLUSIONS}

Patients and clinicians might assume that musculoskeletal pain is a natural part of getting older, that it involves irreversible mechanical injury, that they cannot treat it safely, or that they should anticipate it worsening. The findings in this research challenge such assumptions and indicate instead that musculoskeletal pain is not associated with advancing age, is frequently intermittent, and often remits. These results encourage guarded optimism about the prognosis of musculoskeletal pain in older adults. Addressing risk factors associated with pain such as depression, obes- ity, and overall poor health may also yield benefits, although the causal relationships remain unclear.

\section{ACKNOWLEDGMENTS}

The research reported in this article was supported by Contracts N01-HC-85,239, N01-HC-85,079 through N01-HC-85,086, N01-HC-35,129, N01 HC-15,103, N01HC-55,222, N01-HC-75,150, N01-HC-45,133, and Grant HL080295 from the National Heart, Lung, and Blood Institute, with additional contribution from the National Institute of Neurological Disorders and Stroke. Additional support was provided through AG-023,629, AG-15,928, AG-20,098, and AG-027,058 from the National Institute on Aging. A full list of principal CHS investigators and institutions can be found at http://www.chs-nhlbi.org/pi. htm. Additional support was provided by the following career development awards: K23 AG032867 (Whitson), K23 MH093591 (Thielke), K23 AG030986 (Chaudhry), and the John A. Hartford Foundation Research Fellowship Award and Harvard Claude D. Pepper Older Americans Independence Center P30-AG-028,717 (Kim).

Author Contributions: ST: Conceived of the study, conducted preliminary analyses, interpreted the data, summarized the findings, and prepared the first draft of the manuscript. HW: Helped to design the study, assisted in analyses and interpretation of data, and wrote sections of the discussion. PD: Performed or repeated analyses and helped to interpret the results. AO: Reviewed the results, assisted in interpretation, and wrote sections of the discussion. PK: Reviewed the results, wrote part of the results section, and extensively edited the text. SC: Helped interpret the results and wrote parts of the discussion. NZ: Helped plan the survival analyses, reviewed the results, assisted in interpretation, and wrote the description of the survival methods. DK: Helped develop the analytical plan, reviewed the results, and wrote part of the discussion section. NS: Reviewed the results and assisted in writing the discussion of clinical relevance. JS: Reviewed the results and wrote parts of the background and discussion related to pain beliefs. AA: Conducted analyses, helped in interpreting results, and reviewed methods and findings. PC: Helped in the design of the study, reviewed results, and assisted in interpreting data, especially selection of covariates. AN: Helped design the study, reviewed the results, and helped in interpreting the data.

Sponsor's Role: The sponsor had no direct role in the analysis of the data or preparation of the manuscript.

\section{REFERENCES}

1. Herr KA, Mobily PR, Wallace RB et al. Leg pain in the rural Iowa $65+$ population. Prevalence, related factors, and association with functional status. Clin J Pain 1991;7:114-121.

2. Peat G, McCarney R, Croft P. Knee pain and osteoarthritis in older adults: A review of community burden and current use of primary health care. Ann Rheum Dis 2001;60:91-97.

3. Rosenberg AE. Bones, joints, and soft-tissue tumors. In: Kumar V, Abbas AK, Fausto N et al., eds. Robbins and Cotran Pathologic Basis of Disease, Professional Edition, 8th Ed. Philadelphia, PA: Saunders Elsevier, 2009, pp 1205-1210.

4. Appelt CJ, Burant BC, Siminoff LA et al. Health beliefs related to aging among older male patients with knee and/or hip osteoarthritis. J Gerontol A Biol Sci Med Sci 2007;62A:184-190. 
5. Sale J, Gignac M, Hawker G. How "bad" does the pain have to be? A qualitative study examining adherence to pain medication in older adults with osteoarthritis Arthritis Rheum 2006;55:272-278.

6. Gignac M, Davis A, Hawker G et al. "What do you expect? You're just getting older": A comparison of perceived osteoarthritis-related and agingrelated health experiences in middle- and older-age adults Arthritis Rheum 2006;55:905-912.

7. Mallen CD, Peat G. Discussing prognosis with older people with musculoskeletal pain: A cross-sectional study in general practice. BMC Fam Pract 2009;10:50.

8. Hochberg MC. Quantitative radiography in osteoarthritis: Analysis. Baillieres Clin Rheumatol 1996;10:421-428.

9. Harkness EF, Macfarlane GJ, Silman AJ et al. Is musculoskeletal pain more common now than 40 years ago?: Two population-based cross-sectional studies. Rheumatology 2005;44:890-895.

10. Thomas E, Peat G, Harris L et al. The prevalence of pain and pain interference in a general population of older adults: Cross-sectional findings from the North Staffordshire Osteoarthritis Project (NorStOP). Pain 2004;110: 361-368.

11. Macfarlane GJ, Beasley M, Jones EA et al. The prevalence and management of low back pain across adulthood: Results from a population-based cross-sectional study (the MUSICIAN study). Pain 2012;153:27-32.

12. Kamaleri Y, Natvig B, Ihlebaek CM et al. Change in the number of musculoskeletal pain sites: A 14-year prospective study. Pain 2009;141:25-30.

13. Elliott AM, Smith BH, Hannaford PC et al. The course of chronic pain in the community: Results of a 4-year follow-up study. Pain 2002;99:299 307.

14. Mallen CD, Peat G, Porcheret M et al. The prognosis of joint pain in the older patient: General practitioners' views on discussing and estimating prognosis. Eur J Gen Pract 2007;13:166-168.

15. Hochberg MC. Prognosis of osteoarthritis. Ann Rheum Dis 1996;55:685688.

16. Fried LP, Borhani NO, Enright $P$ et al. The Cardiovascular Health Study: Design and rationale. Ann Epidemiol 1991;1:263-276.

17. Schein JR, Kosinski MR, Janagap-Benson C et al. Functionality and healthstatus benefits associated with reduction of osteoarthritis pain. Curr Med Res Opin 2008;24:1255-1265.

18. Rogers MW, Wilder FV. The association of BMI and knee pain among persons with radiographic knee osteoarthritis: A cross-sectional study. BMC Musculoskelet Disord 2008;9:163.

19. Thielke SM, Fan MY, Sullivan M et al. Pain limits the effectiveness of collaborative care for depression. Am J Geriatr Psychiatry 2007;15:699-707.

20. Diehr P, Yanez D, Derleth A et al. Age-specific prevalence and years of healthy life in a system with three health states. Stat Med 2008;27:13711386.

21. Radloff LS. The CES-D scale: A self-report depression scale for research in the general population. App Psychol Meas 1977;1:385-401.

22. Whitson HE, Thielke S, Diehr P et al. Patterns and predictors of recovery from exhaustion in older adults: The Cardiovascular Health Study. J Am Geriatr Soc 2011;59:207-213.

23. Fisher LD, Lin DY. Time-dependent covariates in the Cox proportionalhazards regression model. Annu Rev Public Health 1999;20:145-157.

24. Leveille SG, Ling S, Hochberg MC et al. Widespread musculoskeletal pain and the progression of disability in older disabled women. Ann Intern Med 2001;135:1038-1046.

25. Eggermont LH, Bean JF, Guralnik JM et al. Comparing pain severity versus pain location in the MOBILIZE Boston study: Chronic pain and lower extremity function. J Gerontol A Biol Sci Med Sci 2009;64A:763-770.

26. Dobscha SK, Corson K, Perrin NA et al. Collaborative care for chronic pain in primary care: A cluster randomized trial. JAMA 2009;301:1242-1252.

27. Unutzer J, Hantke M, Powers D et al. Care management for depression and osteoarthritis pain in older primary care patients: A pilot study. Int J Geriatr Psychiatry 2008;23:1166-1171.

28. Gomes T, Mamdani MM, Dhalla IA et al. Opioid dose and drug-related mortality in patients with nonmalignant pain. Arch Intern Med 2011;171:686-691.
29. Gibson SJ, Helme RD. Age differences in pain perception and report: A review of physiological, psychological, laboratory and clinical studies. Pain Rev 1995;2:111-137.

30. Health Center for Statistics Health, United States, 2006 With Chartbook on Trends in the Health of Americans. Atlanta, GA: Centers for Disease Control and Prevention, 2006.

31. Dionne CE, Dunn KM, Croft PR. Does back pain prevalence really decrease with increasing age? A systematic review Age Ageing 2006;35:229-234.

32. Smith AK, Cenzer IS, Knight SJ et al. The epidemiology of pain during the last 2 years of life. Ann Intern Med 2010;153:563-569.

33. Reid MC. What can population-based studies tell us about pain in the last years of life? Ann Intern Med 2010;153:612-613.

34. van Dijk GM, Dekker J, Veenhof C et al. Course of functional status and pain in osteoarthritis of the hip or knee: A systematic review of the literature. Arthritis Rheum 2006;55:779-785.

35. Mallen CD, Peat G, Thomas E et al. Prognostic factors for musculoskeletal pain in primary care: A systematic review. Br J Gen Pract 2007;57:655661.

36. Dieppe P, Cushnaghan J, Tucker M et al. The Bristol "OA500 study": Progression and impact of the disease after 8 years. Osteoarthritis Cartilage 2000;2000:63-68.

37. Neogi T, Felson D, Niu J et al. Association between radiographic features of knee osteoarthritis and pain: Results from two cohort studies. BMJ 2009;339:b2844.

38. McAlindon TE, Cooper C, Kirwan JR et al. Knee pain and disability in the community. Br J Rheumatol 1992;31:189-192.

39. Arden N, Nevitt MC. Osteoarthritis: Epidemiology. Best practice \& research. Clin Rheumatol 2006;20:3-25.

40. Leveille SG, Jones RN, Kiely DK et al. Chronic musculoskeletal pain and the occurrence of falls in an older population. JAMA 2009;302:2214 2221.

41. Thomas E, Mottram S, Peat G et al. The effect of age on the onset of pain interference in a general population of older adults: Prospective findings from the North Staffordshire Osteoarthritis Project (NorStOP). Pain 2007;129:21-27.

42. Zhang W, Moskowitz RW, Nuki G et al. OARSI recommendations for the management of hip and knee osteoarthritis, part I: Critical appraisal of existing treatment guidelines and systematic review of current research evidence. Osteoarthritis Cartilage 2007;15:981-1000.

43. Hay EM, Foster NE, Thomas E et al. Effectiveness of community physiotherapy and enhanced pharmacy review for knee pain in people aged over 55 presenting to primary care: Pragmatic randomised trial. BMJ 2006;333:995.

44. Jenkinson CM, Doherty M, Avery AJ et al. Effects of dietary intervention and quadriceps strengthening exercises on pain and function in overweight people with knee pain: Randomised controlled trial. BMJ 2009;339:3170.

45. Solomon DH, Avorn J, Wang PS et al. Prescription opioid use among older adults with arthritis or low back pain. Arthritis Rheum 2006;55:35-41.

46. Racine M, Tousignant-Laflamme Y, Kloda LA et al. A systematic literature review of 10 years of research on sex/gender and pain perception-Part 2: Do biopsychosocial factors alter pain sensitivity differently in women and men? Pain 2012;153:619-635.

47. Leveille SG, Zhang Y, McMullen W et al. Sex differences in musculoskeletal pain in older adults. Pain 2005;116:332-338.

48. Bergman S, Jacobsson LT, Herrstrom P et al. Health status as measured by SF-36 reflects changes and predicts outcome in chronic musculoskeletal pain: A 3-year follow up study in the general population. Pain 2004;108:115-123.

49. Idler EL, Benyamini Y. Self-rated health and mortality: A review of twenty-seven community studies. J Health Soc Behav 1997;38:21-37.

50. Horgas AL, Elliott AF, Marsiske M. Pain assessment in persons with dementia: Relationship between self-report and behavioral observation. J Am Geriatr Soc 2009;57:126-132. 